\title{
A Relevant Fuzzy Logic Algorithm to Better Optimize Electricity Consumption in Individual Housing
}

\author{
S. Bissey, S. Jacques and J.-C. Le Bunetel \\ University of Tours (France), GREMAN CNRS UMR 7347, Tours (France) \\ 7 avenue Marcel Dassault, 37200 Tours (France) \\ Phone number: +332473613 25, e-mail: sebastien.bissey@univ-tours.fr, sebastien.jacques@univ-tours.fr, \\ lebunetel@univ-tours.fr
}

\begin{abstract}
In this article, a Fuzzy Logic algorithm (MATLAB environment) is descripted to better predict and manage electricity consumption in individual housing. Several measurements were performed in 3 houses to have an idea of typical electrical energy consumptions.

Without any prediction model, the simulation results of the management system exhibit that it is not possible to smooth all peak demands. In particular, this smoothing is in chronological sequence. Using the prediction and management modeling, the highest peak demands can be forecasted. As a consequence, if the house is composed of a storage system, all stored electricity can be reinjected during the highest peak periods.

Finally, the system proposed here provides safety guarantees, and particularly during AC-line disconnection.
\end{abstract}

\section{Key words}

Demand side management, load forecasting, smart grid, electricity consumption.

\section{Introduction}

Throughout the world, the electrical energy consumption has constantly increased since the 1970s [1]. In particular, electricity consumption has been multiplied by 3.2 from 1973 to 2010 . This strong growth is about $17,7 \mathrm{TWh}$.

In recent years, the management of electricity consumption has become increasingly important, notably with the arrival of new technologies such as electric vehicles and connected objects (e.g., smartphones, computers), and sometimes with a low energy consumption but in large quantities. These loads consume more and more energy at specific times.

In France, peak demand and overall electricity use have continuously increased since 1960 [2]. For example, in 2000 , the peak load recorded in winter reached $73.8 \mathrm{GW}$. Then, this value increased regularly to reach $96.7 \mathrm{GW}$ in 2010. Over the same period, the annual electricity consumption in France increased from about $440 \mathrm{GWh}$ in 2000 to $513 \mathrm{GWh}$ in 2010 , an increase of $1.5 \%$ per year on average.
L. G. Swan et al. and A. Grandjean et al. have demonstrated the relevance to model the end-use electricity consumption in the residential domain [3, 4]. They have particularly highlighted two consumption models: top-down and bottom-up. Top-down model considers electricity use as a global value and attributes an electrical energy consumption that depends on the main characteristics of the buildings in a country (e.g., household equipment rate, average useful duration for each device). Bottom-up model computes electricity demand for one dwelling or an urban zone. So, it considers the house as a unique entity and multiply its consumption to obtain the overall electricity consumption for a residential area. Bottom-up model uses some information such as the consumption of each electrical devices, weather data and human behaviors. Today, bottom-up model is considered as the model to be used to determine the impact of new energy sources or technologies on the demand for electrical energy overtime.

Electricity consumption management is crucial to warrant the balance between supply and demand of electric power. Optimal solutions must be offered to encourage people to prevent electricity waste with regard to simplicity and transparency for the customer. A demand side management strategy has recently been proposed by A. Tascikaraoglu et al. [5]. They have particularly pointed out that additional electricity savings of about $2.9 \%$ may be recorded in a smart building. Other authors have also proposed intelligent systems in charge of directly communicating and interacting with the consumers to minimize the peak demand [6].

Demand side management may be composed of three strategies. The first one consists in predicting the electrical energy that could be totally used by the consumer. The second one consists in forecasting the electricity consumption, knowing that a storage system could be used (batteries, flywheels, hydrogen and fuel cells). This storage system is entirely justified because the electricity consumption may be smoothed. In this case, the electrical energy should be reinjected during peak demand. The last one consists in controlling the loads in individual housing 
both to postpone their operation and shift the electricity consumption.

This article is reinforcing the demand side management strategies that are currently in use in literature. In particular, the aim is to get a better understanding of usage and specific consumer patterns to better predict the electricity consumption in individual housing. This study allows to reinforce the bottom-up approach. As the prediction is accurate for individual housing, the electricity consumption of an urban zone can be accurate. At the moment, a few research activities in that field can be found [7-10]. In this paper, the Fuzzy Logic algorithm is used to reach the objectives described previously. A relevant methodology is described to propose the development of a smart system to optimize electricity consumption in individual housing.

Finally, a discussion is proposed both to point out the advantages of the method and its limitations.

\section{Methodology}

Figure 1 shows an example of an electrical energy management system. In this paper, we propose to combine a power consumption management strategy using a storage system and a load control system. The ultimate challenge is to offer a solution to consumer in simplicity and transparency (the consumption behaviors must not be disturbed).

In this paper, the strategy consists in using all the existing loads in the individual housing. However, the aim is to add a powerful and reliable communication system both to enable a dialog between these loads and create a real-time monitoring of their electricity consumption. Another function to be added consists in using an electronic switch to turn on and turn off each electric device to manage distributed load shedding.

Regarding the simplicity and transparency offered to the end user, A. Tascikaraoglu et al. and Ditiro Setlhaolo et al. have recently classified the main electric devices in individual housing $[5,11]$. For instance, this classification is a function of controllability (to be turned on or turned off), flexibility (how much time the system can be delayed in comparison with usual time of operation), and time-ofuse. An example is given in Table I.

As can be seen in Figure 1, a storage system may be implemented both to prevent peak demand and shift electricity consumption. It has a positive impact on the pricing system for electricity. For example, in France, the challenge is to shift electrical energy consumption in offpeak periods.

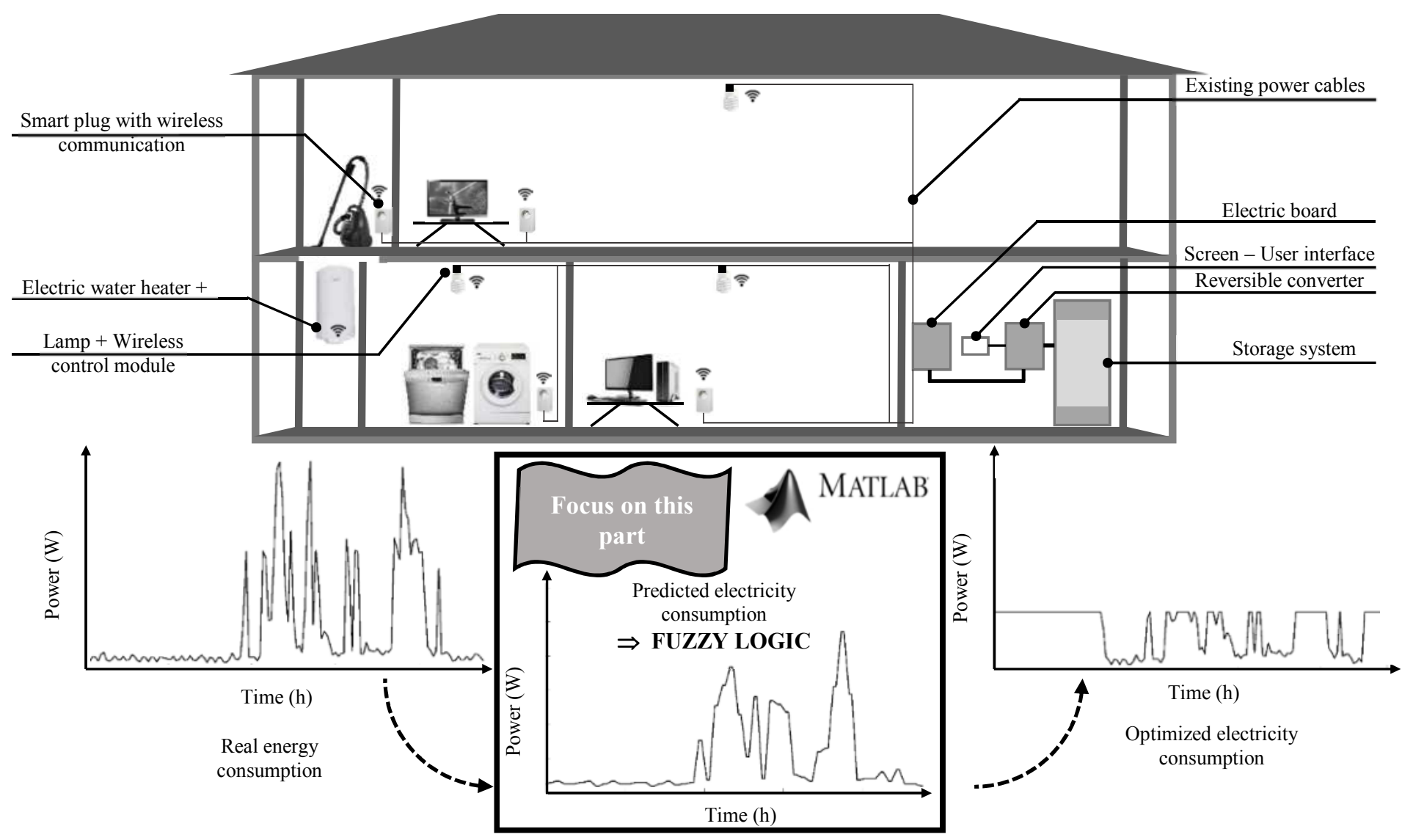

Fig. 1. Example of a "smart house" using Fuzzy Logic prediction and electrical energy management. 
TABLE I - CLASSIFICATION OF THE ELECTRICAL APPLIANCES IN THE SMART HOME [5, 11].

\begin{tabular}{|c|c|c|c|c|c|}
\hline Appliances & Type & $\begin{array}{c}\text { Flexibility } \\
\text { classification }\end{array}$ & $\begin{array}{c}\text { Flexibility } \\
\text { time [min] } \\
\text { (Assumption) }\end{array}$ & $\begin{array}{c}\text { Rated } \\
\text { power } \\
{[\mathrm{kW}]}\end{array}$ & Time-of-use (Average time) \\
\hline Washing Machine & Controllable & Night loads & \pm 120 & 2.5 & 48 weeks/year -4 times a week \\
\hline Dishwasher & Controllable & Night loads & \pm 120 & 1.2 & 48 weeks/year -5 times a week \\
\hline Dryer & Controllable & Flexible & \pm 30 & 2.75 & 32 weeks $/$ year -2 times a week \\
\hline Refrigerator & Controllable & Flexible & \pm 5 & 0.25 & 365 days/year \\
\hline Electric oven & Controllable & Flexible & \pm 15 & 2.25 & 48 weeks $/$ year $-1.5 \mathrm{~h} /$ week \\
\hline Electric vehicle & Controllable & Flexible & \pm 120 & 3 & $9 \mathrm{~h} / \mathrm{recharge}$ \\
\hline Electric heater & Controllable & Flexible & \pm 30 & 1.5 & $100 \mathrm{kWh} / \mathrm{year} / \mathrm{m}^{2}$ \\
\hline Water heater & Controllable & Flexible & \pm 120 & 2.2 & 365 days $/$ year -70 min./day \\
\hline Cooker hood & Non-controllable & Inflexible & - & 0.10 & 335 days/year -40 min./day \\
\hline Microwave & Non-controllable & Inflexible & - & 1.25 & 48 weeks $/$ year $-1.5 \mathrm{~h} /$ week \\
\hline Coffee maker & Non-controllable & Inflexible & - & 0.60 & 335 days $/$ year -10 min./day \\
\hline Hair dryer & Non-controllable & Inflexible & - & 0.5 & 48 weeks $/$ year -30 min./day \\
\hline LCD television & Non-controllable & Inflexible & - & 0.1 & 335 days $/$ year $-4 \mathrm{~h} /$ day \\
\hline Computer & Non-controllable & Inflexible & - & 0.075 & 240 days $/$ year $4 \mathrm{~h} /$ day \\
\hline Iron & Non-controllable & Inflexible & - & 0.9 & 48 weeks $/$ year $-5 \mathrm{~h} /$ week \\
\hline
\end{tabular}

In this paper, the electrical energy prediction and management is based on a simulation interface using the MATLAB environment. This interface will be detailed in the last section of the manuscript (see Results and Discussion). So, an algorithm is developed. Then, the code could be implemented in a microcontroller (STM32F4). Finally a prototype of the smart build will be built.

A key objective of this algorithm is to prevent peak demand by turning off electric devices, or using the storage system to reinject electricity in their own power grid.

Depending on the user's choice, the electrical management system uses firstly the storage system and secondly, the load control or vice versa. When the load control is possible, the system tries to turn off electrical loads when possible to smooth the demand.

Figure 2 shows a typical problem that could frequently occur. If the management system has no idea of the user's lifestyles and his consumption patterns, it is not possible to charge and discharge the storage system at the right time. With the prediction capacity, the system does not smooth each peak, but it tries firstly to smooth high peak demand.

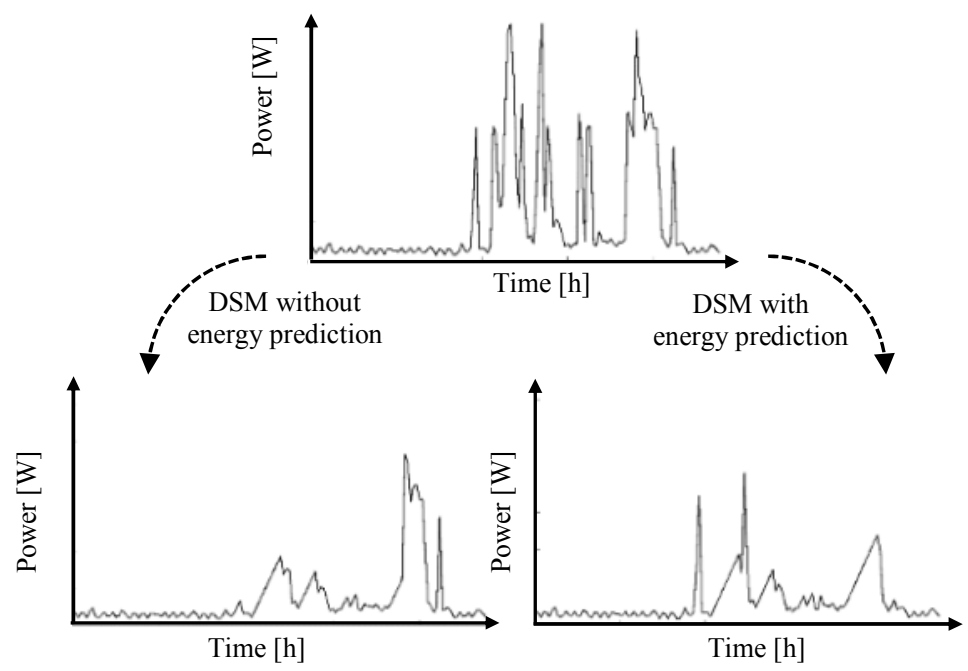

Fig. 2. Comparison between an electricity management system with and without consumption prediction.
The prediction of electricity consumption is of main importance to build the system. As a consequence, the prediction algorithm is an input of the electrical demand management system. The prediction model is created using the Fuzzy Logic method. An accurate prediction model gives the possibility to reach an optimal planning and operation of the electrical management system.

\section{Fuzzy Logic implementation}

Most of prediction models have inputs such as the day's position (weekday/weekend/holyday, month and/or season), the temperatures and the loads databases [12].

Mathematical models meet a major obstacle in load forecasting because of the non-linear relationships between inputs (past load, past and predicted temperature) and outputs (predicted load). Fuzzy Logic offers a new approach with a logic table composed of IF-THEN rules such as IF temperature is low, THEN electricity consumption is high. The Fuzzy Logic appears as a great way to predict energy consumption, because human behavior could be considered as random and at the same time, foreseeable.

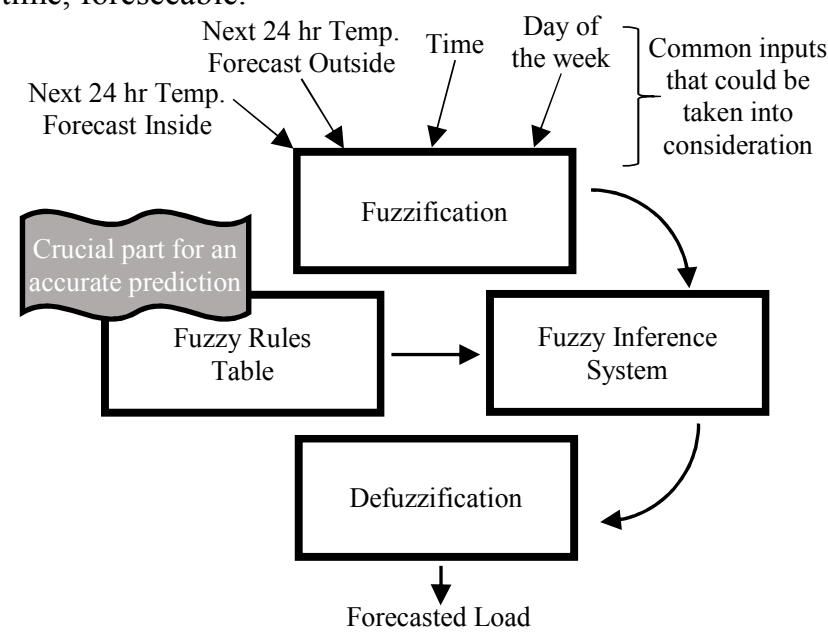

Fig. 3. Block diagram of a Fuzzy Logic system for short term load prediction. 
As shown in Figure 3, the first step of the Fuzzy Logic prediction is the fuzzification which consists in converting digital inputs values to fuzzy inputs. The three relevant inputs for load forecasting are time, weekday and temperature mismatch (difference between indoor and outdoor temperatures).

Time variable is considers as the main input. Indeed, a survey of the electrical consumption has been done in order to have a database of the power consumption for the main devices in individual housing. This survey gives the mean useful duration for each device and most of them was multiple of $30 \mathrm{~min}$. So, time is divided into forty-eight trapezoidal parts corresponding to $30 \mathrm{~min}$. Figure 4 shows the membership function of the time variable used in the fuzzification.

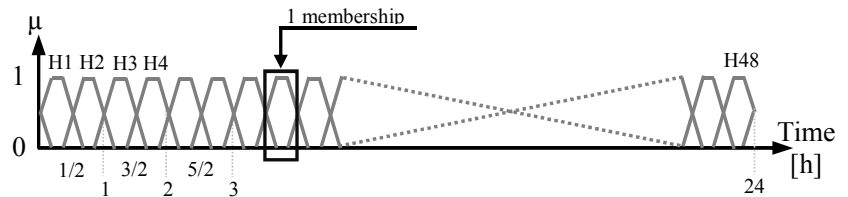

Fig. 4. Membership function of the time variable (input).

The accuracy of the prediction increases with the number of split for each input. It also increases the amount of time to have an accurate prediction.

Figure 5 shows the electricity consumption divided into 300 triangular membership functions.

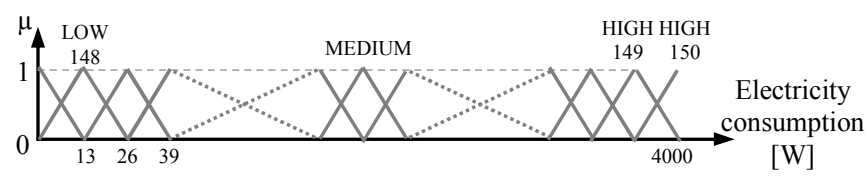

Fig. 5. Triangular membership function for forecasted load (output variable).

Regarding the inputs, the number of membership functions does not change the computation time. However, to the output, the number of membership functions increases the computation time.

The electrical consumption is divided into 300 membership functions, a precision of $\pm 5 \mathrm{~W}$ is defined for an electrical consumption of $3 \mathrm{~kW}$. Simulations have demonstrated that an increase of this value does not have a significant change in the prediction model accuracy.

Regarding the Fuzzy Logic method, the fuzzy rules are the most important parts to define. The fuzzy rules are composed of a table with 1344 columns. For each column, there is one Time/Day/ $\Delta \mathrm{T}$ combination. So, these are $48 * 7 * 4=1344$ possibilities. The heuristic learning is stored in terms of "IF-THEN" rules.

A part of the 1344 rules is as follows:

-If ( $\Delta \mathrm{T}$ is N3) and (Day is D1) and (Time is H4) then (Load is L2)

-If $(\Delta \mathrm{T}$ is P2) and (Day is D6) and (Time is H20) then (Load is H6)

The training system is shown Fig. 6.

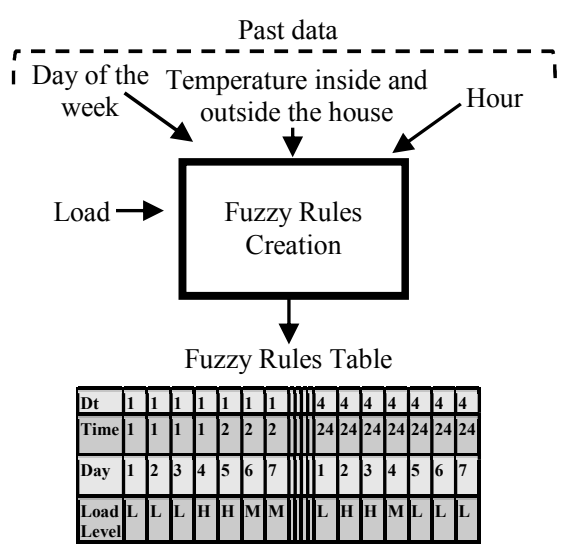

Fig. 6. Training phase of the prediction system.

\section{Results and Discussion}

Three houses have been equipped with a load measurement system to experiment the prediction model. Each house was instrumented during 30 days.

In this section of the manuscript, the relevance of the Fuzzy Logic algorithm is presented.

A typical house was considered (4 residents). Using the instrumentation method, the electricity consumption patterns were:

-Peak demand from 10 am to $2 \mathrm{pm}$.

-Peak demand from $6 \mathrm{pm}$ to $9 \mathrm{pm}$.

Two case studies were considered. The first one, without any prediction model. The second one used the Fuzzy Logic algorithm to predict and manage electricity consumption.

Figure 7 shows the electricity consumption of the house during $24 \mathrm{~h}$. In particular, without the use of the prediction model, the storage system was constantly used to smooth the peak demands. Moreover, from a specific period of time (i.e., from $7 \mathrm{pm}$ to $12 \mathrm{pm}$ ), the storage system was empty. So, the management system was not able to remove the peaks.

---- Real consumption (from measurements)

-Electricity consumption from the management system

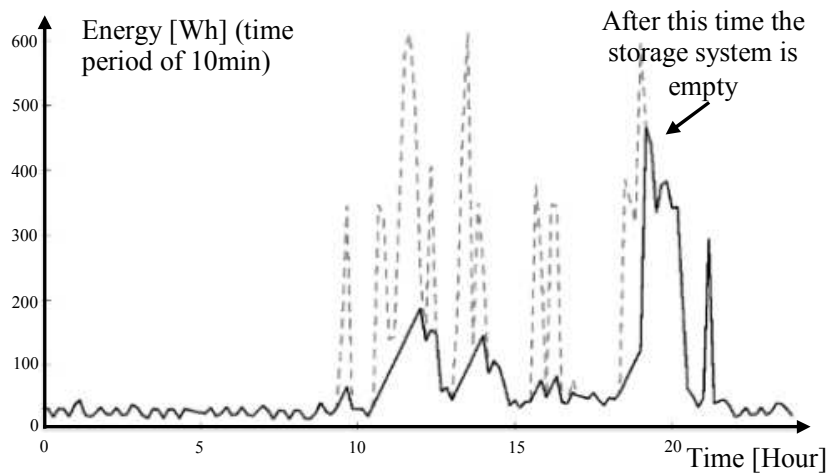

Fig. 7. Management system without prediction of the electricity consumption.

Figure 8 shows the electricity consumption of the house during $24 \mathrm{~h}$. In comparison with Figure 9, in that case, the Fuzzy Logic algorithm was taken into consideration. From this prediction model, most of peak demands was 
forecasted. The capacity of the storage system was smartly used, in particular to smooth the most important peak demands.

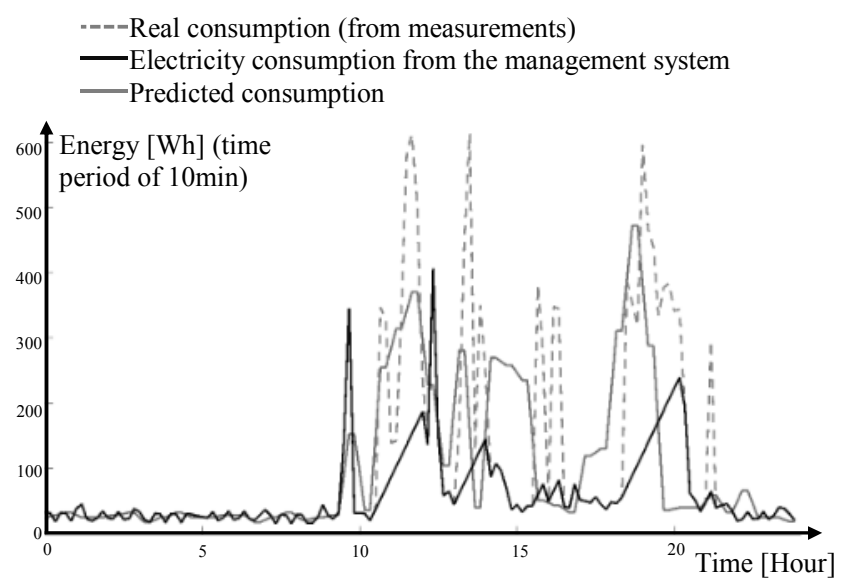

Fig. 8. Management system with prediction of the electricity consumption.

One important challenge, for the next future, is to implement the Fuzzy Logic algorithm and the management system in a microcontroller unit (MCU). This MCU will be in charge of controlling the loads to optimize electricity consumption. It will also manage the storage system, and a reversible AC-DC converter will be necessary to convert the signals from the storage system to the AC line of the house.

As a consequence, a demonstrator of a "smart building" will be proposed in the next future. This paper revealed the importance of the prediction modeling to build this demonstrator.

\section{Conclusions}

In this paper, an electrical energy management system, that implements an overall electricity consumption prediction model, was proposed. This model was established using the Fuzzy Logic method.

Several individual houses were instrumented to highlight the importance of the prediction model. Without any forecasted modeling, the electricity management system can smooth peak demands, but the most energy-intensive devices are not taken into consideration. With the use of the Fuzzy Logic algorithm, it is possible to firstly manage the most energy-intensive devices.

If the house is composed of a storage system, the Fuzzy Logic algorithm is helpful to better manage its capacity.

Finally, this system provides safety guarantees. Blackout cannot be observed (in case of general disconnection or for exceeding contract power).

\section{Acknowledgement}

These research activities are currently supported by "Région Centre Val-de-Loire" (research project number: 2015-00099656). The authors of this manuscript thank our colleagues from this institution who provided insight and expertise that greatly assisted the project.

\section{References}

[1] IEA Statistics (C) OECD/IEA 2014. Electric power consumption ( $\mathrm{kWh}$ per capita) [Internet]. [cited 2016 October 15]. Retrieved from http://data.worldbank.org/ indicator/EG.USE .ELEC.KH.PC.

[2] IEA Statistics (C) OECD/IEA 2014. Electric power consumption (kWh per capita) [Internet]. [cited 2016 October 15]. Retrieved from http://data.worldbank.org/ indicator/EG.USE .ELEC.KH.PC?locations=FR.

[3] Swan, L. G., \& Ugursal, V. I. (2009). Modeling of end-use energy consumption in the residential sector: A review of modeling techniques. Renewable and Sustainable Energy Reviews, 13(8), 1819-1835.

[4] Grandjean, A., Adnot, J., \& Binet, G. (2012). A review and an analysis of the residential electric load curve models. Renewable and Sustainable Energy Reviews, 16(9), 65396565 .

[5] Tascikaraoglu, A., Boynuegri, A. R., \& Uzunoglu, M. (2014). A demand side management strategy based on forecasting of residential renewable sources: A smart home system in Turkey. Energy and Buildings, 80, 309-320.

[6] Mohsenian-Rad, A.-H., Wong, V. W. S., Jatskevich, J., Schober, R., \& Leon-Garcia, A. (2010). Autonomous Demand-Side Management Based on Game-Theoretic Energy Consumption Scheduling for the Future Smart Grid. IEEE Transactions on Smart Grid, 1(3), 320-331.

[7] Pappas, S. S., Ekonomou, L., Karamousantas, D. C., Chatzarakis, G. E., Katsikas, S. K., \& Liatsis, P. (2008). Electricity demand loads modeling using AutoRegressive Moving Average (ARMA) models. Energy, 33(9), 13531360.

[8] Jovanović, R. Ž., Sretenović, A. A., \& Živković, B. D. (2015). Ensemble of various neural networks for prediction of heating energy consumption. Energy and Buildings, 94, 189199.

[9] Barak, S., \& Sadegh, S. S. (2016). Forecasting energy consumption using ensemble ARIMA-ANFIS hybrid algorithm. International Journal of Electrical Power \& Energy Systems, 82, 92-104.

[10] Chenthur Pandian, S., Duraiswamy, K., Christober Asir Rajan, C., \& Kanagaraj, N. (2006). Fuzzy approach for short term load forecasting. Electric Power Systems Research, 76(6-7), 541-548.

[11] Setlhaolo, D., \& Xia, X. (2016). Combined residential demand side management strategies with coordination and economic analysis. International Journal of Electrical Power \& Energy Systems, 79, 150-160.

[12] Hippert, H. S., Pedreira, C. E., \& Souza, R. C. (2001). Neural networks for short-term load forecasting: a review and evaluation. IEEE Transactions on Power Systems, 16(1), 44-55. 